\title{
Lower Lactate Levels and Lower Intracellular pH in Patients with IDH-Mutant versus Wild-Type Gliomas
}

\author{
D.J. Wenger, (D).P. Steinbach, (D) O. Bähr, (D) U. Pilatus, and (D) E. Hattingen
}

\begin{abstract}
BACKGROUND AND PURPOSE: Preclinical evidence points toward a metabolic reprogramming in isocitrate dehydrogenase (IDH) mutated tumor cells with down-regulation of the expression of genes that encode for glycolytic metabolism. We noninvasively investigated lactate and $\mathrm{Cr}$ concentrations, as well as intracellular $\mathrm{pH}$ using ${ }^{1} \mathrm{H}$ /phosphorus $31\left({ }^{31} \mathrm{P}\right) \mathrm{MR}$ spectroscopy in a cohort of patients with gliomas.
\end{abstract}

MATERIALS AND METHODS: Thirty prospectively enrolled, mostly untreated patients with gliomas met the spectral quality criteria (World Health Organization II [ $n=7]$, III $[n=16]$, IV [ $n=7]$; IDH-mutant [ $n=23]$; IDH wild-type [ $n=7]$; 1p/19q codeletion [ $n=9]$ ). MR imaging protocol included 3D ${ }^{31} \mathrm{P}$ chemical shift imaging and ${ }^{1} \mathrm{H}$ single-voxel spectroscopy (point-resolved spectroscopy sequence at $\mathrm{TE}=30 \mathrm{~ms}$ and $\mathrm{TE}=97 \mathrm{~ms}$ with optimized echo spacing for detection of 2-hydroxyglutarate) from the tumor area. Values for absolute metabolite concentrations were calculated (phantom replacement method). Intracellular $\mathrm{pH}$ was determined from ${ }^{31} \mathrm{P}$ chemical shift imaging.

RESULTS: At TE $=97 \mathrm{~ms}$, lactate peaks can be fitted with little impact of lipid/macromolecule contamination. We found a significant difference in lactate concentrations, lactate $\mathrm{Cr}$ ratios, and intracellular $\mathrm{pH}$ when comparing tumor voxels of patients with $I D H$-mutant with those of patients with $I D H$ wild-type gliomas, with reduced lactate levels and near-normal intracellular $\mathrm{pH}$ in patients with IDH-mutant gliomas. We additionally found evidence for codependent effects of 1p/19q codeletion and IDH mutations with regard to lactate concentrations for World Health Organization tumor grades II and III, with lower lactate levels in patients exhibiting the codeletion. There was no statistical significance when comparing lactate concentrations between IDH-mutant World Health Organization II and III gliomas.

CONCLUSIONS: We found indirect evidence for metabolic reprogramming in IDH-mutant tumors with significantly lower lactate concentrations compared with IDH wild-type tumors and a near-normal intracellular $\mathrm{pH}$.

ABBREVIATIONS: ATP = adenosine triphosphate; CRLB = Cramer-Rao Lower Bound; 2-HG = 2-hydroxyglutarate; IDHmut = isocitrate dehydrogenase mutant; IDHwt = isocitrate dehydrogenase wild-type; $\mathrm{MM}=$ macromolecules; $\mathrm{NHEl}=$ sodium-hydrogen antiporter 1 ; $\mathrm{pH}_{\mathrm{i}}=$ intracellular $\mathrm{pH}$; $\mathrm{PRESS}=$ pointresolved spectroscopy sequence; SVS = single-voxel spectroscopy; WHO = World Health Organization

A s first described by Otto Warburg in the 1930s, many tumor cells show increased glycolysis even in the presence of oxygen, likely through the activation of the key signaling phosphatidylinositol-3 kinase/protein kinase B-pathway and hypoxia-inducible

Received October 17, 2019; accepted after revision May 3, 2020.

From the Departments of Neuroradiology (K.J.W., U.P., E.H.), and Neurooncology (J.P.S., O.B.), University Hospital Frankfurt, Frankfurt am Main, Germany; German Cancer Consortium Partner Site (K.J.W., J.P.S., O.B., U.P., E.H.), Frankfurt am Main/ Mainz, Germany; and German Cancer Research Center (K.J.W., J.P.S., O.B., U.P., E.H.), Heidelberg, Germany.

This work was supported by Stiftung Tumorforschung Kopf-Hals (Wiesbaden, Germany) and Frankfurter Forschungsförderung (Frankfurt, Germany).

Please address correspondence to Katharina J. Wenger, MD, Department of Neuroradiology, University Hospital Frankfurt, Schleusenweg 2-16, 60528, Frankfurt, Germany, e-mail: katharina.wenger@kgu.de

Indicates article with supplemental on-line table.

http://dx.doi.org/10.3174/ajnr.A6633 factor $\alpha$ activation. ${ }^{1,2}$ In addition, some tumor cells show mitochondrial defects and are dependent on glycolytic adenosine triphosphate (ATP) production. ${ }^{3-8}$ Glycolytic cancer cells use overexpressed and/or overactivated $\mathrm{H}^{+}$-ATPases, ${ }^{9-12}$ sodium-hydrogen antiporter 1 (NHE1) of the SLC9A family, ${ }^{13-17}$ carbonic anhydrases IX and XII, ${ }^{18,19}$ and monocarboxylate-H+ efflux cotransporters of the SLC16A family ${ }^{20-23}$ to export protons and Lac produced by lactate dehydrogenases as glycolytic end products. ${ }^{24}$ As a result, the proton gradient between the intracellular and extracellular space is reversed, causing an acidification of the extracellular space. The death of surrounding normal brain cells in an acidic environment increases the infiltrative potential of cancer cells. ${ }^{11,25}$

Mutations in the isocitrate dehydrogenase (IDH) 1 or IDH 2 genes define a subgroup of gliomas with prolonged overall survival and slower growth in comparison with $I D H$ wild-type (IDHwt) tumors of the same grade. ${ }^{26}$ A profound alteration in 
the epigenetic profile of these tumors (G-CIMP phenotype) is considered the basis of their specific behavior. There is increasing evidence that these tumors are less glycolytic than IDHwt tumor cells.

Chesnelong et $\mathrm{al}^{27}$ were able to show an IDH mutation-dependent silencing of lactate dehydrogenase A in vitro in conjunction with down-regulation of hypoxia-inducible factor $\alpha$ through 2-hydroxyglutarate (2-HG) dependent promotion of hypoxia-inducible factor $\alpha$ degradation, examining human glioma tissues and brain tumor stem cells with pyrosequencing-based DNA methylation analysis. Using carbon $13\left({ }^{13} \mathrm{C}\right) \mathrm{MR}$ spectroscopy, the same group found that, unlike in glioblastoma cells, hyperpolarized $\left(1-{ }^{13} \mathrm{C}\right)$ Lac produced from $\left(1-{ }^{13} \mathrm{C}\right)$ pyruvate was not elevated in IDH1-mutant (IDH1mut) glioma cells. This finding was associated with lactate dehydrogenase $\mathrm{A}$ and monocarboxylate transporter 1 and 4 silencing. ${ }^{28}$ Izquierdo-Garcia et $\mathrm{al}^{29}$ investigated Lac levels in vitro in genetically engineered cell models transducted with a lentiviral vector coding for the wild-type IDH1 gene and for the R132H IDH1-mutant gene using ${ }^{1} \mathrm{H}-\mathrm{MR}$ spectroscopy. They found that intracellular Lac levels dropped significantly in the IDHmut cells compared with IDHwt (extracellular not investigated).

In accordance with these results, Khurshed et $\mathrm{al}^{30}$ observed in vitro in HCT116 IDH1wt/R132H knock-in cells that IDHmut cancer cells show a higher basal respiration compared with IDHwt cancer cells. Consequently, inhibition of the IDH mutation shifted the metabolism by decreasing oxygen consumption and increasing glycolysis. IDHwt glioma cells seem to have a typical Warburg phenotype, whereas in IDHmut glioma cells, the tricarboxylic acid cycle is the predominant metabolic pathway.

Chromosomal losses of $1 \mathrm{p}$ and $19 \mathrm{q}$, which are observed in oligodendroglial tumors, seem to be frequently associated with $I D H$ gene mutations. ${ }^{31}$ Codependent effects of $1 \mathrm{p}$ deletion and IDHmut-dependent NHE1 gene promotor methylation lead to silencing of the NHE1 gene. As a result, these tumors are more sensitive to the acid load resulting from active glycolysis. Genes of other key enzymes in glycolysis such as the glucose transporter solute carrier family 2 member 1 (SLC2A1) and the Lac transporter solute carrier family 16 member 1 (SLC16A1) are also located on $1 \mathrm{p}$ and affected by the $1 \mathrm{p} / 19 \mathrm{q}$ codeletion. ${ }^{27}$

All of these results suggest a metabolic reprogramming in IDHmut tumor cells with a down-regulation of the expression of genes that encode for glycolytic metabolism. ${ }^{30}$ The aim of this study was to investigate resulting metabolic profiles in patients in vivo, by noninvasively analyzing Lac concentrations and intracellular $\mathrm{pH}\left(\mathrm{pH}_{\mathrm{i}}\right)$ in a cohort of patients with gliomas with known molecular status.

\section{MATERIALS AND METHODS \\ Study Design}

We prospectively enrolled 38 patients with mostly untreated World Health Organization (WHO) II-IV gliomas. All subjects provided written informed consent, and the study was approved by our institutional review board (Ethics Committee, University Hospital Frankfurt, Germany, project No: SIN-04-2014). IDH mutation status was determined by immunostaining (IDH1 Anti-IDH1 R132 antibody), Infinium Human Methylation 450 BeadChip analysis, ${ }^{32}$ or DNA sequencing.

\section{MR Imaging}

MR imaging experiments were performed on a clinical 3T MR imaging scanner with a double-tuned ${ }^{1} \mathrm{H} /{ }^{31} \mathrm{P}$ volume head coil.

MR imaging protocols included the following sequences:

- T2-weighted TSE in 3 orthogonal planes.

- 3D T1-weighted gradient echo.

- ${ }^{1} \mathrm{H}$ decoupled ${ }^{31} \mathrm{P}$ MR spectroscopic imaging with 3D chemical shift imaging.

- $2 \mathrm{D}{ }^{1} \mathrm{H}-\mathrm{MR}$ spectroscopic imaging.

- Two ${ }^{1} \mathrm{H}$ single-voxel spectroscopy (SVS) point-resolved spectroscopy sequence (PRESS) measurements at $\mathrm{TE}=30 \mathrm{~ms}$ and $\mathrm{TE}=97 \mathrm{~ms}$ with optimized echo spacing for detection of 2HG from the tumor area as defined on T2WI TSE.

The 2 SVS sequences were acquired from identical target positions, typically with volumes of $8 \mathrm{~mL}(20 \times 20 \times 20 \mathrm{~mm})$, with minimal inclusion of healthy-appearing tissue and avoiding necrosis. Voxels were positioned on T2-weighted images with prior knowledge of previously acquired standard MR imaging, which included T1-weighted images after use of gadolinium-based contrast agent. Voxel placement was adjusted in 3 orthogonal planes. Details on the acquisition protocol of the sequences evaluated in this report are listed in Table 1.

\section{Data Analysis}

Spectra were reviewed independently by 2 experienced MR imaging specialists (E.H., U.P., both with $>10$ years of experience in MR spectroscopy) for quality, and spectra of insufficient quality (large line width, insufficient signal-to-noise, large artifacts at visual inspection) were not included in the analysis. For all remaining cases, the full width at half maximum of the Cr or Cho signal was below $0.1 \mathrm{ppm}$. Mean signal-to-noise ratio, defined here as the ratio of the maximum in the spectrum-minus-baseline over the analysis window to twice the root-mean square deviation (residuals), was $11 \pm 3.8$ for $\mathrm{TE}=30$ spectra and $9.8 \pm 3.4$ for $\mathrm{TE}=97$ spectra. Cramer-Rao Lower Bounds (CRLBs) of Cr and Cho as given by LCModel (Version 6.3-1C; http://www.lcmodel. $\mathrm{com} /$ ) were below $15 \%$ (Cr: $97 \%$ of cases $<10 \%$; Cho: $93 \%$ of cases $<10 \%)$.

${ }^{1} \mathrm{H}$ data were analyzed in the frequency domain with LCModel. ${ }^{33}$ For single-voxel sequences at TE $=30 \mathrm{~ms}$ and $\mathrm{TE}=$ $97 \mathrm{~ms}$, a 3D volume-localized basis set was simulated using NMRScopeB which is implemented in jMRUI (Version 5.2; www.mrui.uab.es/mrui/mrui_download/). ${ }^{34}$ The basis data set included 2-HG, NAA, glutamate, Cr, glutamine, Cho, mIns, and $\mathrm{Lac}$ in addition to the dataset for simulation of the macromolecules (MM) and lipids as provided by LCModel. We deliberately chose only 8 main metabolites in addition to MM and lipids to be included in the basis set. According to the principle of parsimony, a model with more parameters is less likely to reproducibly predict in vivo datasets with highly varying metabolites. ${ }^{35}$

Simulation was based on the assumption of a $20 \times 20 \times$ $20 \mathrm{~mm}$ volume, homogeneously filled with the respective metabolites. The basis set was validated with phantom data. Individual 
Table 1: Acquisition protocol of sequences evaluated in this report

\begin{tabular}{|c|c|c|c|c|c|}
\hline Sequence & $\begin{array}{c}\text { Section Thickness/ } \\
\text { Voxel Size }\end{array}$ & TR, Flip Angle & TE & $\begin{array}{c}\text { Matrix; } \\
\text { Resolution }\end{array}$ & Pulse Details \\
\hline $\begin{array}{l}\text { T2WI TSE in } 3 \\
\text { orthogonal planes }\end{array}$ & $5 \mathrm{~mm}$ & $3300 \mathrm{~ms}$ & $102 \mathrm{~ms}$ & & \\
\hline $\begin{array}{l}\text { 3D TIWI gradient } \\
\text { echo }\end{array}$ & $1.5 \mathrm{~mm}$ & $8.2 \mathrm{~ms}$ & & $3.62 \mathrm{~ms}$ & \\
\hline 3D FID ${ }^{31} \mathrm{P} \mathrm{CSI}$ & $30 \times 30 \times 25 \mathrm{~mm}$ & $2000 \mathrm{~ms} ; 60^{\circ}$ & $2.3 \mathrm{~ms}$ & $\begin{array}{l}8 \times 8 \times 8 \text { at } 240 \\
\times 240 \times 200 \\
\mathrm{~mm}^{3}, \text { FOV } \\
\text { extrapolated to } \\
16 \times 16 \times 16\end{array}$ & \\
\hline 2D ${ }^{1} \mathrm{H}-\mathrm{MRSI}$ & $12.5 \mathrm{~mm}$ & $1500 \mathrm{~ms} ; 90^{\circ}$ & $30 \mathrm{~ms}$ & $16 \times 16$ & \\
\hline $\begin{array}{l}{ }^{1} \mathrm{H} \text { single-voxel } \\
\text { PRESS }\end{array}$ & $\begin{array}{l}20 \times 20 \times 20 \mathrm{~mm} \\
\text { PRESS localized } \\
\text { volume }\end{array}$ & $3000 \mathrm{~ms} ; 90^{\circ}$ & $30 \mathrm{~ms}$ & & \\
\hline $\begin{array}{l}{ }^{1} \mathrm{H} \text { single-voxel } \\
\text { PRESS }\end{array}$ & $\begin{array}{l}20 \times 20 \times 20 \mathrm{~mm} \\
\text { PRESS-localized } \\
\text { volume }\end{array}$ & $3000 \mathrm{~ms} ; 90^{\circ}$ & $97 \mathrm{~ms}$ & & $\begin{array}{l}\text { Sinc-shaped excitation pulse (duration } \\
2.6 \mathrm{~ms} \text {, Slice selection gradient } \\
\text { amplitude } 33.95 \mathrm{mT} / \mathrm{m} \text {, BWTP } 8.75 \text { ), } \\
\text { Mao refocusing pulse (duration, } \\
2.6 \mathrm{~ms} \text {, section-refocusing gradient } \\
\text { amplitude, } 2.7171 \mathrm{mT} / \mathrm{m} \text {; BWTP 6) }\end{array}$ \\
\hline
\end{tabular}

Note:-MRSI indicates MR spectroscopic imaging; BWTP, bandwidth-time product; FID, free induction decay; CSI, chemical shift imaging.

metabolite concentrations (Lac, total $\mathrm{Cr}$ ) were calculated using the phantom replacement technique described by Tofts $^{36}$ based on signal amplitudes at $\mathrm{TE}=97(\mathrm{Lac})$ and $\mathrm{TE}=30$ (total $\mathrm{Cr}$ ). The correction factors $c_{\mathrm{T} 1}$ and $\mathrm{c}_{\mathrm{T} 2}$ at $3 \mathrm{~T}$ were determined from previously published data. ${ }^{37,38}$ Because the Tofts formula only provides a global correction for coil loading for transmit/receive coils and does not take local $\mathrm{B}_{1}$ variations into account, which are usually observed at $3 \mathrm{~T}$, the presented method can only be regarded as an estimate of the absolute concentrations. Consequently, the values must be considered as laboratory units resembling absolute concentrations in micromoles. PRESS at TE $=97 \mathrm{~ms}$ was primarily aimed at 2-HG detection ${ }^{39}$ but showed little-to-no lipids and MM in the Lac spectral region and the Lac peak as an inverted pseudosinglet. It was, therefore, used for Lac quantitation. For Cr quantitation, the short TE was chosen as an optimal detection time to avoid signal loss by increased T2-weighting.

$\mathrm{pH}_{\mathrm{i}}$ in predefined tumor voxels was determined from the chemical shift difference between inorganic phosphate and phosphocreatine, following the approach by Petroff et $\mathrm{al}^{40}$ as described in our previous publications. ${ }^{24,41}$

\section{Statistics}

Statistical analysis was performed with Statistica (Version 7.1; StatSoft). Lac/Cr signal ratio, absolute Lac and Cr concentrations, as well as $\mathrm{pH}_{\mathrm{i}}$ were compared using a 2-tailed unpaired $t$ test (IDHmut versus IDHwt; IDHmut WHO II versus IDHmut WHO III [Lac only]; IDH mut and chromosomal losses 1p/19q versus IDHmut without chromosomal losses 1p/19q [Lac only]). Results were considered significant at $P<.05$.

\section{RESULTS}

\section{Patient Characteristics}

Overall, 30 patients completed the full MR imaging examination, and MR spectroscopy data met the quality criteria (WHO II $[n=7]$, III $[n=16]$, IV $[n=7])$. Twenty-three tumors were IDHmut, and 7 tumors were IDHwt as determined by immunostaining (IDH1 R132H antibody) and/or Infinium Human
Methylation 450/850K BeadChip analysis and/or gene sequencing. While there was 1 anaplastic astrocytoma, $I D H$ wild-type (WHO III), all other IDH wild-type tumors corresponded to WHO IV. Tumors from 9 patients showed chromosomal losses of $1 \mathrm{p}$ and $19 \mathrm{q}$ as determined by fluorescence in situ hybridization and/or Infinium Human Methylation 450/850K BeadChip analysis. One patient with an IDHmut diffuse astrocytoma was excluded from SVS data analysis due to artifacts from extracranial lipid signals, while 1 patient with an IDHwt glioblastoma was excluded from Lac analysis due to considerable interference between Lac and lipids leading to CRLBs above 30\% for Lac. Three patients had undergone partial resection before study inclusion, one had been treated with chemotherapy (temozolomide), and one, with radiation therapy (one of the patients with partial resection). All of the pretreated patients were those with IDHmut gliomas. Partial resection was performed 4, 14, and 44 months before study inclusion. Details on patient characteristics are listed in Table 2.

\section{Representative Data}

Voxel positioning on T2WI, representative in vivo single voxel MR spectroscopy spectra at TE $97 \mathrm{~ms}$ and TE $30 \mathrm{~ms}$ for tumor tissue with and without IDH mutations and with or without chromosomal losses of $1 p$ and $19 q$ is shown in Fig 1 . MR spectroscopy data include the original spectrum, LCModel spectral fit, estimated baseline, and the individual components Lac, Cr, Lip13b, and MM12. Representative ${ }^{31} \mathrm{P}$ MR spectroscopy spectra for tumor tissue with and without $I D H$ mutation are shown in Fig 2. Details on voxel size for ${ }^{1} \mathrm{H}$ SVS, tumor size, and tumor location are listed in the On-line Table.

\section{Lactate Levels in Glioma}

There was a significant difference in Lac concentration comparing tumor voxels of patients with IDHmut gliomas with those with IDHwt (mean IDHmut $=5.4 \pm 4.1 \mathrm{mmol} / \mathrm{L}$; mean IDHwt $=11.7 \pm 4.3 \mathrm{mmol} / \mathrm{L} ; P<.003, t$ test; Fig 3 ). Because there was no significant difference in comparing the total $\mathrm{Cr}$ 


\section{General}

Age (median) (range) (yr)

Female sex (No.)

Histology according to 2016 WHO Classification of Tumors of the Central Nervous System

Glioblastoma, IDH wild-type, WHO IV (No.)

Gliosarcoma, IDH wild-type, WHO IV (No.)

Glioblastoma IDH-mutant, WHO IV (No.)

Anaplastic astrocytoma, IDH wild-type, WHO III (No.)

Anaplastic astrocytoma, IDH-mutant, WHO III (No.)

Diffuse astrocytoma, IDH wild-type, WHO II (No.)

Diffuse astrocytoma, IDH-mutant, WHO II (No.)

Anaplastic oligodendroglioma, IDH-mutant and lp/19q co-deleted, WHO III (No.)

Oligodendroglioma, IDH-mutant and 1p/19q codeleted, WHO II (No.)

$41.1(27.3-78)$
$63 \%(19)$
$17 \%(5)$
$3 \%(1)$
$3 \%(1)$
$3 \%(1)$
$33 \%(10)$
$0 \%(0)$
$10 \%(3)$
$17 \%(5)$
$13 \%(4)$

LCModel: baseline correction splines, implemented MM/lipids and simulated basis set

A

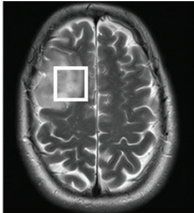

anaplastic oligodendroglioma, WHO III

IDH1R132H mutated $1 p / 19 q \mathrm{LOH}$

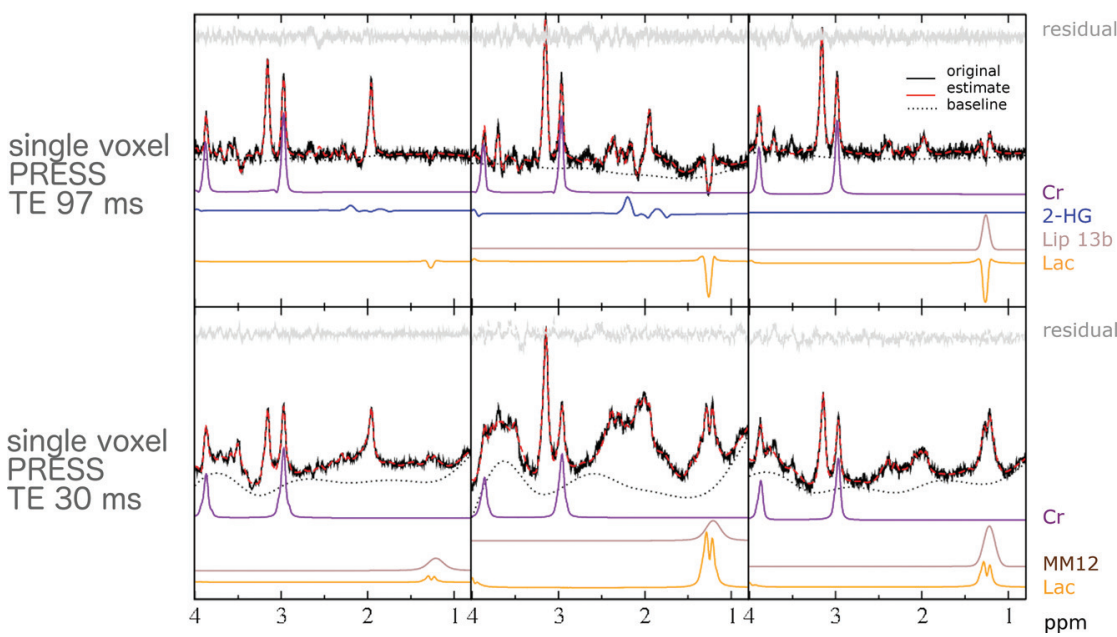

FIG 1. Voxel positioning on T2WI and representative in vivo single-voxel MR spectroscopy spectra at TE $=97 \mathrm{~ms}$ and $\mathrm{TE}=30 \mathrm{~ms}$ for tumor tissue. MR spectroscopic data include original spectrum, LCModel spectral fit, estimated baseline, residual and individual components, Lac, Cr, 2-HG, Lip13b, and MM12 when applicable. Patient $A$ shows evidence of possible codependent effects of Ip deletion and IDH mutations on cell metabolism, with a particularly small lactate signal. With only 1 secondary (IDHmut) glioblastoma in our cohort (patient $B$ ), we were unable to statistically compare the effects between IDHmut and IDHwt glioblastoma as well as IDHmut WHO III and WHO IV gliomas. The relatively high Lac signal of patient $B$ suggests additional effects of highly malignant features such as a selective advantage of tumors cells with higher rates of glycolysis in neovascularized, hypoxic regions and tumor cell necrosis.

ratios bet-ween patients with IDHmut and IDHwt gliomas was maintained, excluding the 2 patients pretreated with radiation therapy or chemotherapy from the cohort $(P=.003$ and $P<.03)$.

To investigate codependent effects of $1 p$ deletion and IDHmut-dependent NHE1 promotor methylation on tumor cell metabolism, we looked at all patients with $I D H$ gene mutations and compared those with chromosomal losses of $1 p$ and $19 q$ with those with no chromosomal losses. We found a significant difference between patients with IDHmut glioma with chromosomal losses of $1 \mathrm{p} / 19 \mathrm{q}$ and those with IDHmut without chromosomal losses with regard to Lac concentration (mean IDHmut codeleted $1 \mathrm{p} / 19 \mathrm{q}$ $=3.0 \pm 2.9 \mathrm{mmol} / \mathrm{L}$; mean IDHmut no codeleted $1 \mathrm{p} / 19 \mathrm{q}=6.7 \pm 4.2 \mathrm{mmol} / \mathrm{L}$; $P<.038$, $t$ test; Fig 4).

Exploring the effects of tumor grade on metabolism, we looked at all patients with $I D H$ gene mutations and compared patients with WHO II with those with WHO III tumor grade. There was no significant difference between IDHmut WHO II and WHO III tumor grades with respect to Lac concentrations (mean IDHmut WHO $\mathrm{II}=5.9 \pm 5.4 \mathrm{mmol} / \mathrm{L}$; mean IDHmut WHO III $=5.2 \pm 3.7 \mathrm{~m} \mathrm{~mol} / \mathrm{L} ; P<.74$, $t$ test; Fig 3 ). Because there was only 1 secondary glioblastoma (IDHmut) in our cohort, we were not able to statisti-

concentration in tumor voxels of patients with IDHmut with those with IDHwt (mean IDHmut $=11.0 \pm 3.3 \mathrm{mmol} / \mathrm{L}$; mean IDHwt $=10.7 \pm 4.3 \mathrm{mmol} / \mathrm{L} ; P=.85, t$ test), we calculated ratios of Lac/Cr. As expected these ratios showed a significant difference between patients with IDHmut and IDHwt gliomas (mean IDHmut $=0.6 \pm 0.6$; mean IDH wt $=1.4 \pm 0.9 ; P<.014, t$ test). Statistical significance for $\mathrm{Lac}$ concentration and $\mathrm{Lac} / \mathrm{Cr}$ cally compare the effects between IDHmut WHO III und WHO IV gliomas.

\section{Changes in Tumor $\mathrm{pH}_{i}$}

We found a significant difference in $\mathrm{pH}_{\mathrm{i}}$ comparing tumor voxels of patients with IDHmut glioma with respective voxels in patients with IDHwt (mean IDHmut $=7.04 \pm 0.02$; mean 
IDHwt $=7.07 \pm 0.03 ; P=.001, t$ test; Fig 5). Statistical significance in $\mathrm{pH}_{\mathrm{i}}$ between patients with IDHmut and IDHwt gliomas was maintained, excluding the 2 patients pretreated

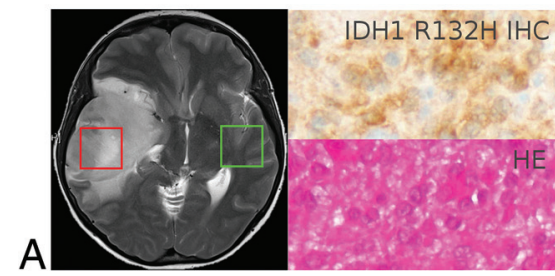

glioblastoma, IDH1R132H mutated

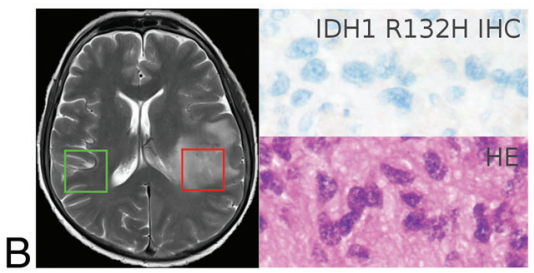

glioblastoma, IDH not mutated

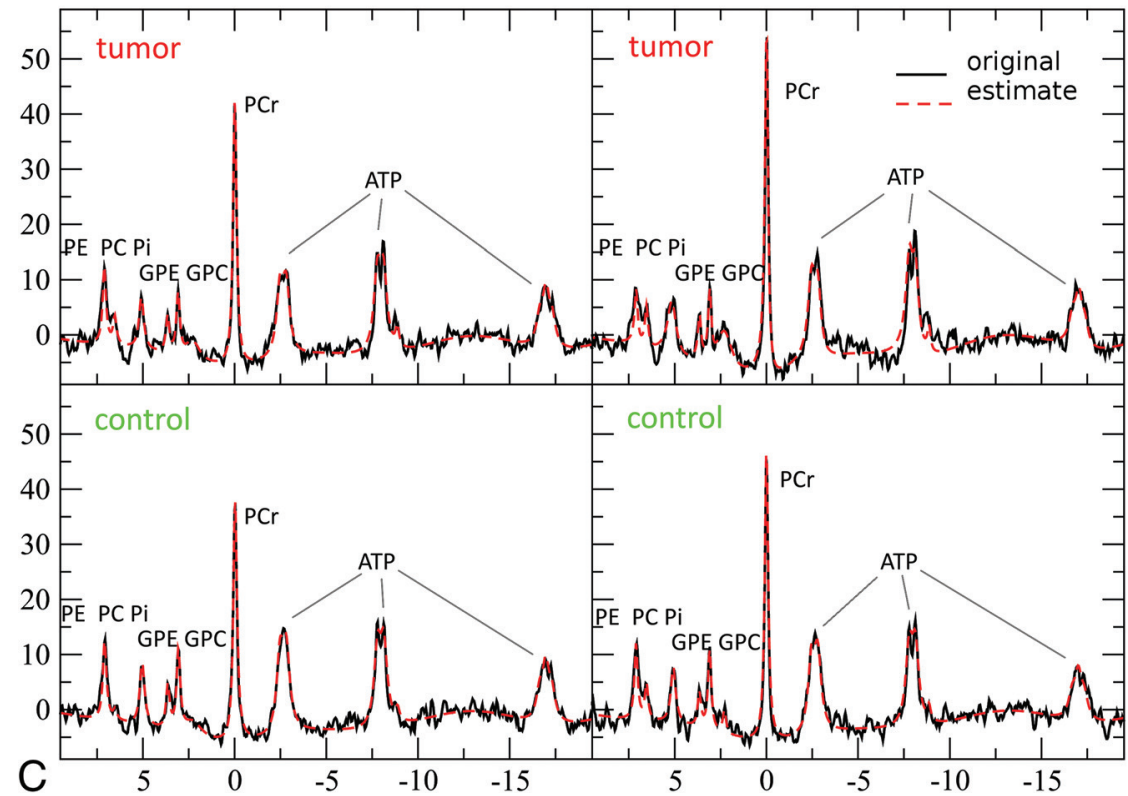

FIG 2. Representative ${ }^{31} \mathrm{P}$ MR spectra (MR spectroscopy) for tumor tissue with and without IDH mutation at 3T. In the upper row ( $A$ and $B$ ), green (control) and red (tumor) boxes indicate voxel positioning on $\mathrm{T} 2 \mathrm{WI}$, while $\mathrm{H} \& \mathrm{E}$ staining and immunostaining of a patient specimen with an antibody for mutant IDHI (RI32H) are shown to the right of the MR images. C, MR spectroscopy data depict the original spectrum as a black line and the spectral fit as red dotted line. ${ }^{40} \mathrm{PCr}$ indicates phosphocreatinine; GPE, glycerophosphoethanolamine; GPC, glycerophosphocholine; PC, phosphocholine; $\mathrm{PE}$, phosphoethanolamine; $\mathrm{Pi}$, inorganic phosphate. Reproduced with permission. with radiation therapy or chemotherapy from the cohort $(P<.001)$. Further results regarding metabolite ratios obtained from $3 \mathrm{D}^{31} \mathrm{P}$ chemical shift imaging have been published previously. ${ }^{39,41}$

\section{DISCUSSION}

Preclinical evidence points toward a metabolic reprogramming in IDHmut tumor cells with down-regulation of the expression of genes that encode for glycolytic metabolism. Results of these metabolic changes could be observed in our noninvasive in vivo study. Most of the investigated IDHwt tumor cells, on the other hand, seemed to behave like typical Warburg tumor cells with a highly glycolytic metabolism. This translated into a significant difference in intratumoral Lac concentrations when comparing patients with IDHmut with those with IDHwt gliomas. The lower Lac production (and possibly excretion) led to a near-normal $\mathrm{pH}_{\mathrm{i}}$ in IDHmut tumors. Therefore, the reversal of the proton gradient between intracellular and extracellular space with acidification of the extracellular space seems to be a characteristic feature of IDHwt tumors. Our findings are well in line with previous in vitro findings. ${ }^{27-30}$ Only Elkhaled et $\mathrm{al}^{42}$ quantified Lac from ${ }^{1} \mathrm{H}$-High Resolution Magic-Angle Spinning ex vivo spectra of biopsy samples of 104 tissue samples from 52 patients with WHO II-IV gliomas and found that Lac concentrations increased with 2-HG concentrations. However, in a later
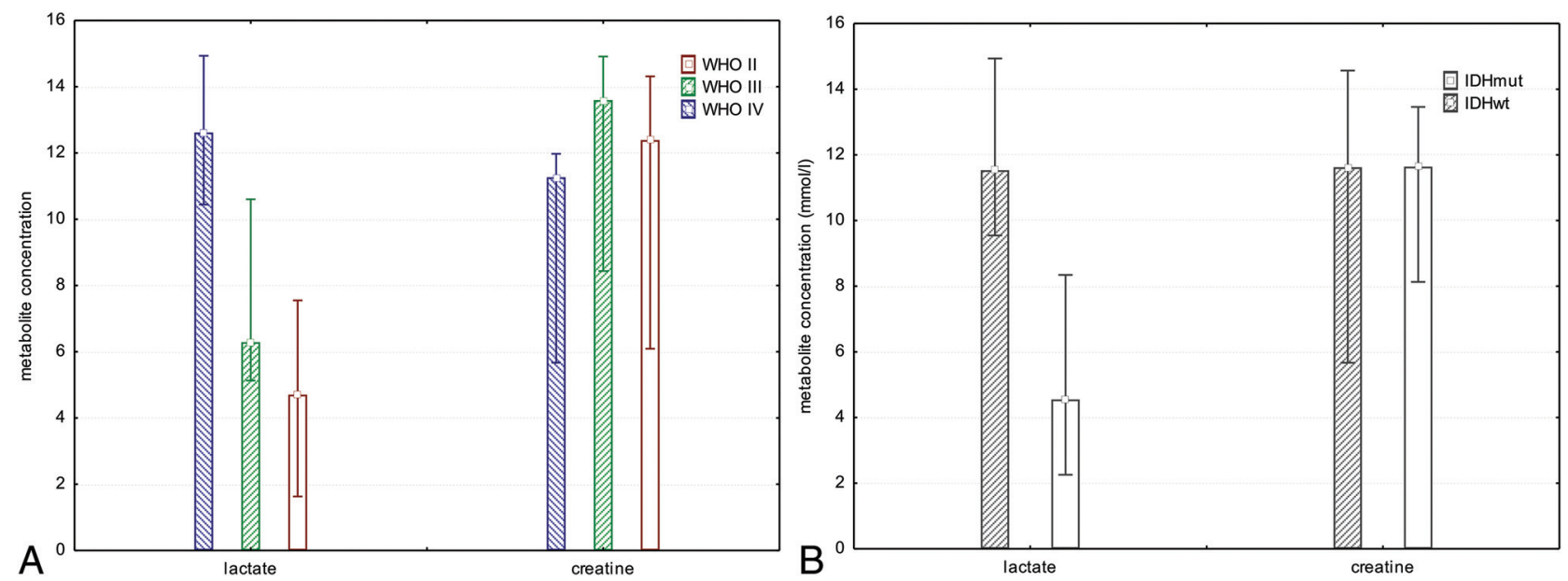

FIG 3. Bar chart showing median, minimum, and maximum of Lac and $\mathrm{Cr}$ concentrations for all tumor grades separately, independent of IDH mutation status $(A)$ and all tumor grades pooled comparing patients with IDHmut with those with IDHwt gliomas (B). There was a significant difference in Lac concentration when comparing tumor voxels of patients with IDHmut gliomas with those with IDHwt $(P<.003, t$ test). 


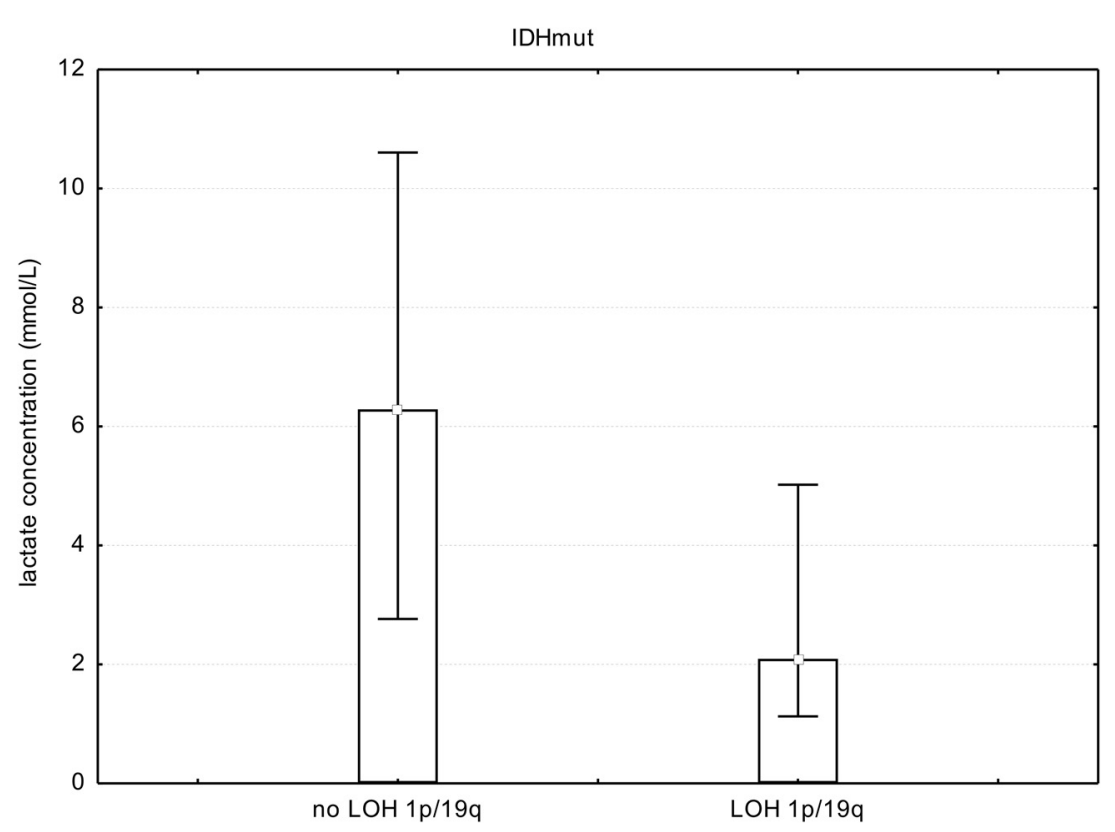

FIG 4. Bar chart showing median, minimum, and maximum Lac concentrations in all patients with IDH gene mutations and WHO II and III gliomas (no WHO IV), comparing those with chromosomal losses of $1 p$ and $19 q$ with those with no chromosomal losses. We found a significant difference in Lac concentrations $(P<.038, t$ test). However, if one compared WHO II with WHO III tumors with IDH gene mutations, there was no significant difference. This finding points toward IDH gene mutations and chromosomal losses as 2 contributing factors to changes in cell metabolism independent of WHO grade. $\mathrm{LOH}$ indicates loss of heterozygosity.

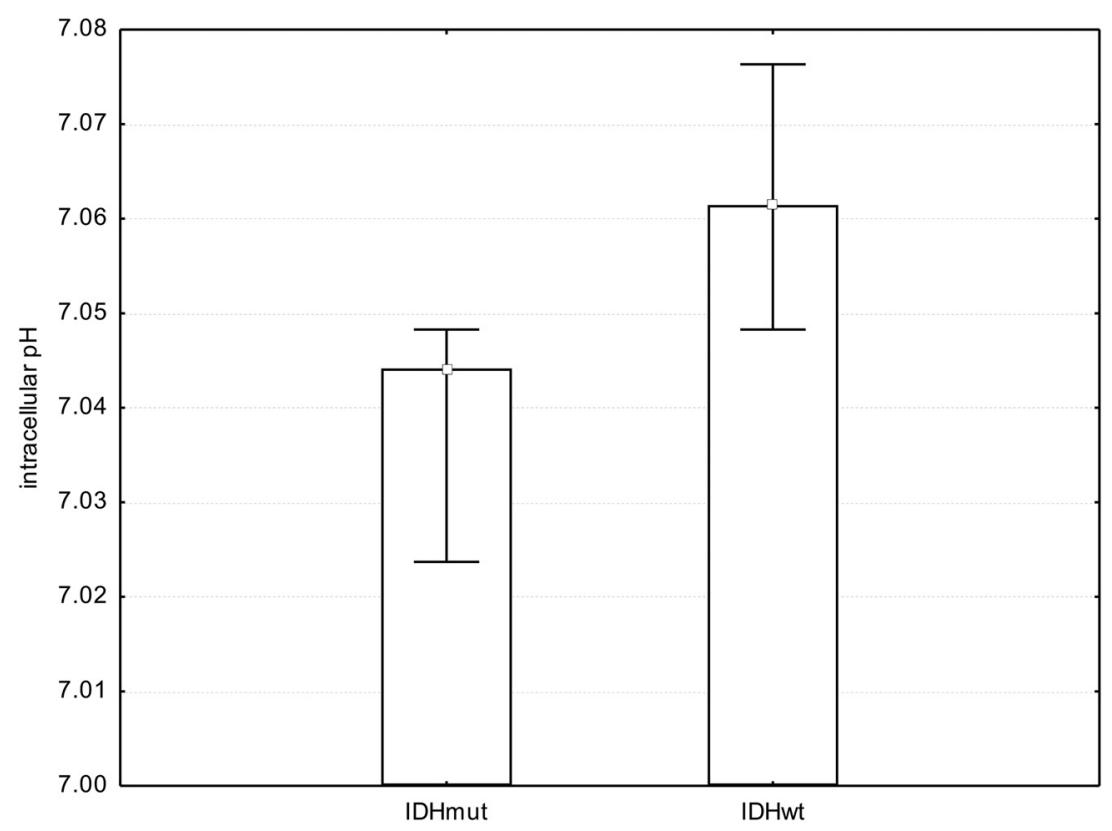

FIG 5. Bar chart showing median, minimum, and maximum $\mathrm{pH}_{\mathrm{i}}$. We found a significant difference in $\mathrm{pHi}$ when comparing tumor voxels of patients with IDHmut gliomas with respective voxels of patients with IDHwt gliomas $(P=.001, t$ test).

report examining ex vivo spectra of biopsy samples of new or recurrent WHO II-IV gliomas with the same method, they stated that the relatively high peaks corresponding to Lac cannot reliably reflect in vivo levels. Death-to-freezing intervals with ischemia of biopsy samples seem to allow anaerobic metabolization of brain glycogen to Lac, contributing to falsely elevated Lac concentrations. ${ }^{43}$

While evidence clearly points toward an IDH genotype dependence of intratumoral lactate levels, it remains uncertain how highly malignant features such as a selective advantage of tumor cells with higher rates of glycolysis in neovascularized, hypoxic regions and tumor cell necrosis enter the equation. ${ }^{44,45}$ It would, therefore, be of interest to compare lactate levels of secondary (IDHmut) glioblastomas with those of primary (IDHwt) glioblastomas and IDHmut WHO III with those of higher malignant IDHmut WHO IV gliomas. Secondary glioblastoma accounted for only approximately $10 \%$ of glioblastomas, ${ }^{46}$ while primary glioblastoma constituted most WHO IV tumors. This was reflected by our cohort with only 1 secondary glioblastoma, impeding statistical comparison between IDHmut and IDHwt glioblastoma as well as IDHmut WHO III and WHO IV gliomas. The relatively high Lac signal of the 1 secondary glioblastoma and the long-known $\mathrm{pH}$ dependence of the invasive capacity of brain tumors ${ }^{11,24}$ suggest additional effects of highly malignant features on Lac levels and $\mathrm{pH}_{\mathrm{i}}$ (Fig 1).

There was no statistical significance when comparing Lac concentrations between IDHmut WHO II and III gliomas. This is in line with the notion that the biologic behavior and the prognosis of WHO II versus III tumors show much fewer differences in IDHmut than in IDHwt tumors. ${ }^{47}$ We additionally found evidence for codependent effects of $1 \mathrm{p} / 19 \mathrm{q}$ codeletion and IDH mutations with regard to Lac concentrations for WHO tumor grades II and III. This finding points toward $I D H$ gene mutations and $1 p / 19 q$ codeletion as 2 contributing factors to changes in cell metabolism independent of WHO grade.

Prior preclinical and clinical studies have discussed possible changes in the phospholipid mechanism related to mutations in $I D H$ genes but were not entirely consistent. ${ }^{29,41,42,48,49}$ Phospholipids are synthesized from phosphatidic acid and 1,2-diacylglycerol intermediates in the synthesis of triacylglycerols. The link to lactate production is pyruvate. Because enzyme activities of both pathways are affected by many factors such as expression, posttranslational 


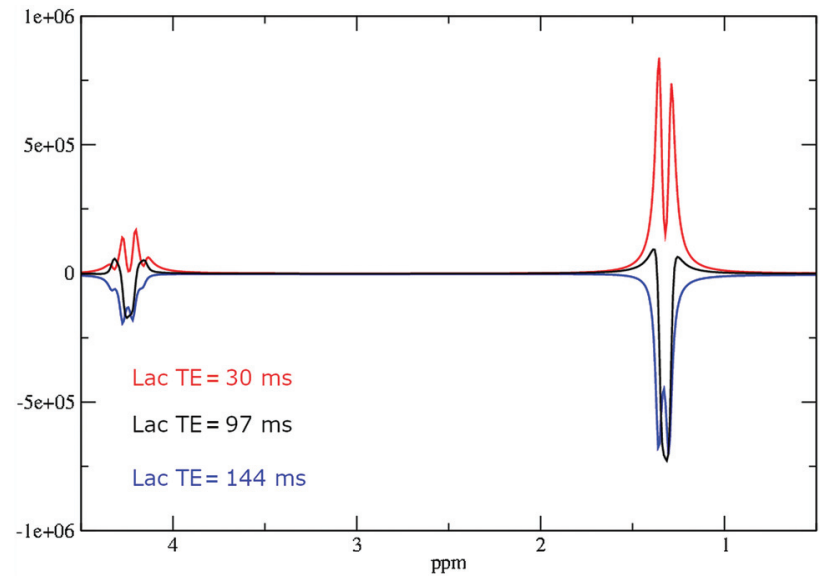

FIG 6. Simulation of Lac PRESS spectra at different TEs using NMRScopeB, which is implemented in jMRUI. The program calculates MR spectra on the basis of a priori knowledge of scalar coupling, chemical shifts, and hardware parameters. The figure shows the real component of the simulated spectrum calculated from a defined amount of lactate in arbitrary units with an additional exponential line broadening of $5 \mathrm{~Hz}$.

modifications, and cofactor levels and may differ between in vivo studies and genetically engineered cell models, current results are not contradicted by previous findings.

The PRESS at TE $=97 \mathrm{~ms}$ was based on the vendor's standard SVS, using a sinc-shaped excitation pulse and a Mao refocusing pulse with $\mathrm{T} 2$ time spacing aimed at 2-HG detection. ${ }^{50}$ In general, the Lac peak at $1.33 \mathrm{ppm}$ is split into a doublet because of J-coupling interaction with the solitary methine proton $(-\mathrm{CH})$. The coupling constant $(\mathrm{J})$ for lactate in vivo is approximately $6.9 \mathrm{~Hz}$. Recording the Lac peak inverted facilitates its detection and discrimination from other resonances such as lipids. ${ }^{51}$ In our study at $\mathrm{TE}=97 \mathrm{~ms}$ (odd multiple of $1 / \mathrm{J}$ ), we were able to record the Lac peak as an inverted pseudosinglet (Fig 6). According to the CRLBs obtained from the LCModel analysis in our cohort, the negative Lac signal can be well-discriminated from the positive signals of MM. While most spectra at $\mathrm{TE}=97 \mathrm{~ms}$ could be fitted without lipids and MM in the Lac spectral region, we found 3 patients with spectra exhibiting Lip13b and 8 patients with MM20 at CRLB of $<20 \%$. In all except one of these spectra, CRLBs for Lac were also below $20 \%$. Only 1 patient's spectrum showed CRLBs for Lac and Lip13 of $>30 \%$, indicating that discrimination between Lac and Lip13 was not possible. This patient was excluded from the analysis. At a $3 \mathrm{~T}$ clinical scanner, the inverted Lac signal might be distorted and significantly reduced in intensity due to an incomplete $180^{\circ}$ pulse at the rim of the PRESS-selected box. ${ }^{51,52}$ While reduced Lac signal intensities in PRESS do not affect our findings comparing patient groups examined with the same MR spectroscopy protocol, absolute Lac concentrations can be affected. The considerable difference in Lac resonance intensity between IDHmut and IDHwt gliomas and between high-grade and low-grade gliomas and a lack of difference in $\mathrm{Cr}$ intensity leave the ratio Lac/Cr relatively insensitive to partial volume effects due to necrotic areas or CSF. It can, therefore, be used as a robust ratio in clinical routine without the need for metabolite quantitation.

\section{Limitations}

With a defined timeframe of the clinical study and a fixed protocol at 1 research scanner in combination with statistical odds of $>70 \%$ of WHO II-III tumors bearing IDH mutations, ${ }^{53}$ we were unable to obtain a more balanced population. We acknowledge that our study is limited by this imbalance.

Pretreated patients may pose limitations on metabolic analysis. In our study cohort, 3 patients had undergone partial resection before the study inclusion, one had been treated with chemotherapy (temozolomide), and one, with radiation therapy. All of the pretreated subjects were patients with IDHmut gliomas. Partial resection was performed 4, 14, and 44 months prior, which we assumed to be a sufficient period to rule out postoperative effects of perioperative ischemia on lactate levels and $\mathrm{pH}_{\mathrm{i}}$. Zheng and Wang ${ }^{54}$ found that lactate levels in a neonatal piglet model were normalized 48-72 hours after hypoxic-ischemic brain injury in the basal ganglia. Statistical significance for Lac concentration, $\mathrm{Lac} / \mathrm{Cr}$ ratios, and $\mathrm{pH}_{\mathrm{i}}$ between patients with IDHmut and IDHwt gliomas was maintained, excluding the 2 patients pretreated with radiation therapy or chemotherapy from the cohort.

With regard to $\mathrm{pH}_{\mathrm{i}}$ values, the general limitations of ${ }^{31} \mathrm{P} \mathrm{MR}$ spectroscopy have to be taken into account. With coarse $8 \times 8 \times 8 k$-space sampling, which is typical for many ${ }^{31} \mathrm{P} \mathrm{MR}$ spectroscopic imaging studies, ${ }^{55}$ results suffer from spreading of signal into adjacent voxels caused by the point spread function. The inherent partial volume effect tends to level focal changes in the position of the signal of inorganic phosphate, which is used to calculate $\mathrm{pH}_{\mathrm{i}}$ values. Because we used only 1 signal to fit inorganic phosphate, the estimated $\mathrm{pH}_{\mathrm{i}}$ rather indicates a deviation to higher values compared with the regular value than providing a number for the real $\mathrm{pH}_{\mathrm{i}}$ in the target region. ${ }^{24} \mathrm{pH}_{\mathrm{i}}$ ranges determined by ${ }^{31} \mathrm{P}$ MR spectroscopy are in line with previous publications by other groups. ${ }^{56,57}$

\section{CONCLUSIONS}

By means of PRESS at TE $=97 \mathrm{~ms}$, with optimized echo spacing for detection of 2-HG, Lac peaks can be fitted with little impact of lipid/MM contamination. We found indirect evidence for metabolic reprogramming in IDHmut tumor cells with a significant difference in Lac concentrations and Lac/Cr ratios compared with IDHwt cells and a near-normal $\mathrm{pH}_{\mathrm{i}}$. Our findings suggest that the prediction of $I D H$ mutation status can be supported by the use of $\mathrm{Lac} / \mathrm{Cr}$ ratios as well as $\mathrm{pH}_{\mathrm{i}}$ as additional MR spectroscopic markers.

Disclosures: Katharina J. Wenger-RELATED: Grant: Stiftung Tumorforschung Kopf-Hals (Wiesbaden, Germany), Frankfurter Forschungsförderung (Frankfurt, Germany), Comments: university funding and charitable foundation funding medical research.* Joachim P. Steinbach—UNRELATED: Consultancy: UCB, Roche; Grants/Grants Pending: UCB; Payment for Lectures Including Service on Speakers Bureaus: Roche, Medac, Boehringer Ingelheim; Travel/Accommodations/Meeting Expenses Unrelated to Activities Listed: Medac, Abbvie.* *Money paid to the institution.

\section{REFERENCES}

1. Chakravarti A, Zhai G, Suzuki Y, et al. The prognostic significance of phosphatidylinositol 3-kinase pathway activation in human gliomas. J Clin Oncol 2004;22:1926-33 CrossRef Medline 
2. Liu Y, Li Y, Tian R, et al. The expression and significance of HIF1alpha and GLUT-3 in glioma. Brain Res 2009;1304:149-54 CrossRef Medline

3. Demetrakopoulos GE, Linn B, Amos H. Rapid loss of ATP by tumor cells deprived of glucose: contrast to normal cells. Biochem Biophys Res Commun 1978;82:787-94 CrossRef Medline

4. Shim H, Chun YS, Lewis BC, et al. A unique glucose-dependent apoptotic pathway induced by c-Myc. Proc Natl Acad Sci USA 1998;95:1511-16 CrossRef Medline

5. Aykin-Burns N, Ahmad IM, Zhu Y, et al. Increased levels of superoxide and $\mathrm{H} 2 \mathrm{O} 2$ mediate the differential susceptibility of cancer cells versus normal cells to glucose deprivation. Biochem $J$ 2009;418:29-37 CrossRef Medline

6. Li Y, Liu L, Tollefsbol TO. Glucose restriction can extend normal cell lifespan and impair precancerous cell growth through epigenetic control of hTERT and p16 expression. FASEB J 2010;24:144253 CrossRef Medline

7. Priebe A, Tan L, Wahl H, et al. Glucose deprivation activates AMPK and induces cell death through modulation of Akt in ovarian cancer cells. Gynecol Oncol 2011;122:389-95 CrossRef Medline

8. Graham NA, Tahmasian M, Kohli B, et al. Glucose deprivation activates a metabolic and signaling amplification loop leading to cell death. Mol Syst Biol 2012;8:589 CrossRef Medline

9. Martinez-Zaguilan R, Lynch RM, Martinez GM, et al. Vacuolar-type $\mathrm{H}(+)$-ATPases are functionally expressed in plasma membranes of human tumor cells. Am J Physiol 1993;265:C1015-29 CrossRef Medline

10. Sennoune SR, Bakunts K, Martínez GM, et al. Vacuolar H+-ATPase in human breast cancer cells with distinct metastatic potential: distribution and functional activity. Am J Physiol, Cell Physiol 2004;286:C1443-52 CrossRef Medline

11. Harguindey S, Orive G, Luis Pedraz J, et al. The role of $\mathbf{p H}$ dynamics and the $\mathrm{Na}+/ \mathrm{H}+$ antiporter in the etiopathogenesis and treatment of cancer: two faces of the same coin-one single nature. Biochim Biophys Acta 2005;1756:1-24 CrossRef Medline

12. Di Cristofori A, Ferrero S, Bertolini I, et al. The vacuolar $\mathbf{H}+$ ATPase is a novel therapeutic target for glioblastoma. Oncotarget 2015;6:17514-31 CrossRef Medline

13. McLean LA, Roscoe J, Jorgensen NK, et al. Malignant gliomas display altered $\mathrm{pH}$ regulation by NHE1 compared with nontransformed astrocytes. Am J Physiol, Cell Physiol 2000;278:C676-88 CrossRef Medline

14. Kumar AP, Quake AL, Chang MKX, et al. Repression of NHE1 expression by PPARgamma activation is a potential new approach for specific inhibition of the growth of tumor cells in vitro and in vivo. Cancer Res 2009;69:8636-44 CrossRef Medline

15. Miraglia E, Viarisio D, Riganti $\mathrm{C}$, et al. $\mathrm{Na}+/ \mathrm{H}+$ exchanger activity is increased in doxorubicin-resistant human colon cancer cells and its modulation modifies the sensitivity of the cells to doxorubicin. Int J Cancer 2005;115:924-29 CrossRef Medline

16. Chiang Y, Chou CY, Hsu KF, et al. EGF upregulates $\mathrm{Na}+/ \mathrm{H}+$ exchanger NHE1 by post-translational regulation that is important for cervical cancer cell invasiveness. J Cell Physiol 2008;214:810-19 CrossRef Medline

17. Cong D, Zhu W, Shi Y, et al. Upregulation of NHE1 protein expression enables glioblastoma cells to escape TMZ-mediated toxicity via increased $\mathrm{H}^{+}$extrusion, cell migration and survival. Carcinogenesis 2014;35:2014-24 CrossRef Medline

18. Chiche J, Ilc K, Laferrière J, et al. Hypoxia-inducible carbonic anhydrase IX and XII promote tumor cell growth by counteracting acidosis through the regulation of the intracellular $\mathbf{p H}$. Cancer Res 2009;69:358-68 CrossRef Medline

19. Swietach P, Hulikova A, Vaughan-Jones RD, et al. New insights into the physiological role of carbonic anhydrase IX in tumour $\mathrm{pH}$ regulation. Oncogene 2010;29:6509-21 CrossRef Medline

20. Pinheiro C, Longatto-Filho A, Scapulatempo C, et al. Increased expression of monocarboxylate transporters 1,2 , and 4 in colorectal carcinomas. Virchows Arch 2008;452:139-46 CrossRef Medline

21. Pinheiro C, Reis RM, Ricardo S, et al. Expression of monocarboxylate transporters 1, 2, and 4 in human tumours and their association with CD147 and CD44. J Biomed Biotechnol 2010;2010:427694 CrossRef Medline

22. Kennedy KM, Dewhirst MW. Tumor metabolism of lactate: the influence and therapeutic potential for MCT and CD147 regulation. Future Oncol 2010;6:127-48 CrossRef Medline

23. Chiche J, Le Fur Y, Vilmen C, et al. In vivo $\mathbf{p H}$ in metabolic-defective Ras-transformed fibroblast tumors: key role of the monocarboxylate transporter, MCT4, for inducing an alkaline intracellular pH. Int J Cancer 2012;130:1511-20 CrossRef Medline

24. Wenger KJ, Hattingen E, Franz K, et al. Intracellular pH measured by $31 \mathrm{P}$-MR-spectroscopy might predict site of progression in recurrent glioblastoma under antiangiogenic therapy. J Magn Reson Imaging 2017;46:1200-08 CrossRef

25. Fais S, Venturi G, Gatenby B. Microenvironmental acidosis in carcinogenesis and metastases: new strategies in prevention and therapy. Cancer Metastasis Rev 2014;33:1095-108 CrossRef Medline

26. Parker SJ, Metallo CM. Metabolic consequences of oncogenic IDH mutations. Pharmacol Ther 2015;152:54-62 CrossRef Medline

27. Chesnelong C, Chaumeil MM, Blough MD, et al. Lactate dehydrogenase A silencing in IDH mutant gliomas. Neuro Oncol 2014;16:686-95 CrossRef Medline

28. Chaumeil MM, Radoul M, Najac C, et al. Hyperpolarized (13)C MR imaging detects no lactate production in mutant IDH1 gliomas: implications for diagnosis and response monitoring. Neuroimage Clin 2016;12:180-89 CrossRef Medline

29. Izquierdo-Garcia JL, Viswanath P, Eriksson P, et al. Metabolic reprogramming in mutant IDH1 glioma cells. PLoS One 2015;10: e0118781 CrossRef Medline

30. Khurshed M, Molenaar RJ, Lenting K, et al. In silico gene expression analysis reveals glycolysis and acetate anaplerosis in IDH1 wildtype glioma and lactate and glutamate anaplerosis in IDH1mutated glioma. Oncotarget 2017;8:49165-77 CrossRef Medline

31. Mur P, Mollejo M, Ruano $Y$, et al. Codeletion of $1 p$ and $19 q$ determines distinct gene methylation and expression profiles in IDHmutated oligodendroglial tumors. Acta Neuropathol 2013;126:27789 CrossRef Medline

32. Wiestler B, Capper D, Hovestadt V, et al. Assessing CpG island methylator phenotype, $1 p / 19 q$ codeletion, and MGMT promoter methylation from epigenome-wide data in the biomarker cohort of the NOA-04 trial. Neuro Oncol 2014;16:1630-38 CrossRef Medline

33. Provencher SW. Estimation of metabolite concentrations from localized in vivo proton NMR spectra. Magn Reson Med 1993;30:672-79 CrossRef Medline

34. Starcõuk Z, Starcõuková J. Quantum-mechanical simulations for in vivo $M R$ spectroscopy: principles and possibilities demonstrated with the program NMRScopeB. Anal Biochem 2017;529:79-97 CrossRef Medline

35. Busch MH, Vollmann W, Mateiescu S, et al. Reproducibility of brain metabolite concentration measurements in lesion free white matter at 1.5 T. BMC Med Imaging 2015;15:40 CrossRef Medline

36. Tofts PS. Spectroscopy: $\mathbf{1 H}$ metabolite concentrations. In: Tofts P, ed. Quantitative MRI of the brain: measuring changes caused by disease. Chichester: John Wiley; 2004:299-340

37. Hattingen E, Pilatus U, Franz K, et al. Evaluation of optimal echo time for $1 \mathrm{H}$-spectroscopic imaging of brain tumors at 3 Tesla. $J$ Magn Reson Imaging 2007;26:427-31 CrossRef Medline

38. Ganji SK, Banerjee A, Patel AM, et al. T2 measurement of J-coupled metabolites in the human brain at 3T: T2 of J-coupled metabolites at 3T. NMR Biomed 2012;25:523-29 CrossRef Medline

39. Wenger KJ, Hattingen E, Harter PN, et al. Fitting algorithms and baseline correction influence the results of non-invasive in vivo quantitation of 2 -hydroxyglutarate with 1 H-MRS. NMR Biomed 2019;32:e4027 CrossRef Medline 
40. Petroff OA, Prichard JW, Behar KL, et al. Cerebral intracellular $\mathbf{p H}$ by $31 \mathrm{P}$ nuclear magnetic resonance spectroscopy. Neurology 1985;35:781-8 CrossRef Medline

41. Wenger KJ, Hattingen E, Franz K, et al. In vivo metabolic profiles as determined by $31 \mathrm{P}$ and short TE $1 \mathrm{H}$ MR-spectroscopy: no difference between patients with IDH wild type and IDH mutant gliomas. Clin Neuroradiol 2019;29:27-36 CrossRef Medline

42. Elkhaled A, Jalbert LE, Phillips JJ, et al. Magnetic resonance of 2hydroxyglutarate in IDH1-mutated low-grade gliomas. Sci Transl Med 2012;4:116ra5 CrossRef Medline

43. Elkhaled A, Jalbert L, Constantin A, et al. Characterization of metabolites in infiltrating gliomas using ex vivo ${ }^{1} \mathrm{H}$ high-resolution magic angle spinning spectroscopy: characterization of metabolites in infiltrating gliomas. NMR Biomed 2014;27:578-93 CrossRef Medline

44. Talasila KM, Røsland GV, Hagland HR, et al. The angiogenic switch leads to a metabolic shift in human glioblastoma. Neuro Oncol 2014;16:v216-93 CrossRef Medline

45. Howe FA, Barton SJ, Cudlip SA, et al. Metabolic profiles of human brain tumors using quantitative in vivo $1 \mathrm{H}$ magnetic resonance spectroscopy. Magn Reson Med 2003;49:223-32 CrossRef Medline

46. Louis DN, Perry A, Reifenberger G, et al. The 2016 World Health Organization Classification of Tumors of the Central Nervous System: a summary. Acta Neuropathol 2016;131:803-20 CrossRef Medline

47. Kickingereder P, Sahm F, Radbruch A, et al. IDH mutation status is associated with a distinct hypoxia/angiogenesis transcriptome signature which is non-invasively predictable with $\mathrm{rCBV}$ imaging in human glioma. Sci Rep 2015;5:16238 CrossRef Medline
48. Esmaeili M, Hamans BC, Navis AC, et al. IDH1 R132H mutation generates a distinct phospholipid metabolite profile in glioma. Cancer Res 2014;74:4898-907 CrossRef Medline

49. Turcan S, Rohle D, Goenka A, et al. IDH1 mutation is sufficient to establish the glioma hypermethylator phenotype. Nature 2012;483:47983 CrossRef Medline

50. Choi C, Ganji SK, DeBerardinis RJ, et al. 2-hydroxyglutarate detection by magnetic resonance spectroscopy in IDH-mutated patients with gliomas. Nat Med 2012;18:624-29 CrossRef Medline

51. Lange T, Dydak U, Roberts TPL, et al. Pitfalls in lactate measurements at 3T. AJNR Am J Neuroradiol 2006;27:895-901 Medline

52. Kelley DA, Wald LL, Star-Lack JM. Lactate detection at 3T: compensating J coupling effects with BASING. J Magn Reson Imaging 1999;9:732-77 CrossRef Medline

53. Yan H, Parsons DW, Jin G, et al. IDH1 and IDH2 mutations in gliomas. N Engl J Med 2009;360:765-73 CrossRef Medline

54. Zheng Y, Wang X-M. Measurement of lactate content and amide proton transfer values in the basal ganglia of a neonatal piglet hypoxic-ischemic brain injury model using MRI. AJNR Am J Neuroradiol 2017;38:827-34 CrossRef Medline

55. Hattingen E, Pilatus U. Brain tumor imaging. Med Radiol Diagn Imaging. Berlin: Springer; 2016

56. Cadoux-Hudson TA, Blackledge MJ, Rajagopalan B, et al. Human primary brain tumour metabolism in vivo: a phosphorus magnetic resonance spectroscopy study. Br J Cancer 1989;60:430-36 CrossRef Medline

57. Maintz D, Heindel W, Kugel H, et al. Phosphorus-31 MR spectroscopy of normal adult human brain and brain tumours. NMR Biomed 2002;15:18-27 CrossRef 